\title{
Are Stem Cell-Based Therapies for Parkinson's Disease Ready for the Clinic in 2016?
}

\author{
Roger A. Barker ${ }^{\mathrm{a}, \mathrm{b}, *}$, Malin Parmar $^{\mathrm{b}}$, Agnete Kirkeby ${ }^{\mathrm{b}}$, Anders Björklund $^{\mathrm{b}}$, Lachlan Thompson ${ }^{\mathrm{c}}$ \\ and Patrik Brundin ${ }^{\mathrm{d}}$ \\ a John van Geest Centre for Brain Repair, Department of Clinical Neurosciences, University of Cambridge, \\ Forvie Site, Cambridge, UK \\ ${ }^{\mathrm{b}}$ Wallenberg Neuroscience Center and Lund Stem Cell Center, Lund University, BMC A11, Lund, Sweden \\ ${ }^{\mathrm{c}}$ Florey Institute for Neuroscience and Mental Health, University of Melbourne, Royal Parade, Parkville, \\ VIC, Australia \\ ${ }^{\mathrm{d}}$ Center for Neurodegenerative Science, Van Andel Research Institute, MI, USA
}

Accepted 2 March 2016

\begin{abstract}
Recent news of an impending clinical cell transplantation trial in Parkinson's disease using parthenogenetic stem cells as a source of donor tissue have raised hopes in the patient community and sparked discussion in the research community. Based on discussions held by a global collaborative initiative on translation of stem cell therapy in Parkinson's disease, we have identified a set of key questions that we believe should be addressed ahead of every clinical stem cell-based transplantation trial in this disorder. In this article, we first provide a short history of cell therapy in Parkinson's disease and briefly describe the current state-of-art regarding human stem cell-derived dopamine neurons for use in any patient trial. With this background information as a foundation, we then discuss each of the key questions in relation to the upcoming therapeutic trial and critically assess if the time is ripe for clinical translation of parthenogenetic stem cell technology in Parkinson's disease.
\end{abstract}

\section{IMPENDING CLINICAL STEM CELL TRIAL RAISES QUESTIONS}

Stem cell-based therapies for Parkinson's disease (PD) are rapidly moving towards clinical trials. Several academic and industry efforts are well under way to produce dopaminergic neurons from stem cells under conditions compliant with use in patients. In December 2015, a press release announced a Phase I/IIa trial in PD using a parthenogenetic stem cell source, resulting in widespread excitement

\footnotetext{
*Correspondence to: Roger A. Barker, John van Geest Centre for Brain Repair, Department of Clinical Neurosciences, University of Cambridge, Forvie Site, Cambridge CB2 OPY, UK. Tel.: +44 1223 331160; Fax: +44 1223 331174; E-mail: rab46@cam.ac.uk.
}

about stem cell therapy for PD in traditional print media, social media and especially in the PD patient community. The California-based biotechnology company International Stem Cell Corporation (ISCO) announced that, working through its wholly owned subsidiary Cyto Therapeutics, it had received approval by the Australian government to conduct a clinical trial in 12 patients with moderate to severe PD at the Royal Melbourne Hospital in Melbourne, Australia [1]. A second press release [2] has indicated that the program is planning to move forward very rapidly, with all of the patients being enrolled in the first quarter of 2016 and interim results being shared in October 2016. This is the first approval of a clinical trial using pluripotent stem cells to treat PD, and for 
that reason places it in the news spotlight. Following the rapid spread via social media, many PD patients worldwide, and their families, became engaged in discussions and have asked whether they should try to sign up for such a study. As with many such exiting news items, however, one should also react with caution, especially since the outcome of this trial can affect the development of other stem cell programs moving towards clinical trials. In the wake of the two press releases from ISCO it can be considered timely to discuss how one should evaluate the opportunities provided to PD patients in this and similar trials being planned by other groups. Without this, the patient community is left trying to interpret complex scientific issues on its own, and individual patients cannot make informed decisions on whether they should seek to participate in the planned trials or not. We have identified several key questions that need discussion ahead of any stem cell-based trial in PD;

1. What is being transplanted, and what is the proposed mechanism of action?

2. What are the pre-clinical safety and efficacy data supporting the use of the proposed stem cell product?

3. Should arguments concerning ethics, riskmitigation or trial logistics outweigh concerns regarding the expected efficacy of the cell and constitute a primary justification for choosing one cell type over another in a clinical trial?

4. What is being claimed regarding the potential therapeutic value of the stem cell-based therapy - better control of symptoms or a cure?

5. What is the regulatory oversight of the trial and is it guided by input from experts in the field?

We will briefly summarise the history and current status of clinical cell-based therapies for PD. Then we will provide short answers to each of the above questions, making reference to the upcoming trial that uses parthenogenetic stem cells as starting material.

\section{A BRIEF HISTORY OF CELL BASED THERAPIES FOR PARKINSON'S DISEASE}

In the late 1970s and early 1980s it was demonstrated by a number of groups, following the pioneering work of Björklund et al. and others, that dopaminergic neurons harvested from the developing fetal midbrain (ventral mesencephalon -VM) could survive grafting in animal models of PD [3]. These cells not only survived transplantation into the adult striatum, but were shown to release dopamine, make and receive connections from the host brain and ameliorate numerous types of motor, as well as other, behavioural deficits in rodent models of PD (reviewed in [4]). Similar results were obtained when human fetal dopamine neurons were xenografted to the striatum of immunosuppressed rats [3]. As a result of the collective success of studies in experimental animals in several independent laboratories, many groups performed open label clinical trials in PD during the late 1980s and 1990s. The rationale was that the adult nigral dopamine cells lost in PD could be replaced by grafted immature human dopaminergic neurons [3, 5]. This approach cannot really be considered to provide a cure, but rather a potentially powerful way to treating the dopamine-responsive motor aspects of PD by affording chronic physiological delivery of dopamine targeted to the striatum.

These clinical studies clearly demonstrated that transplants derived from human 6-9 week old fetal, post-mitotic VM neurons (i.e. immature dopaminergic neurons, but still differentiated past the stem cell stage), could survive, develop and function in a fashion similar to that previously observed in the experimental rodent models. Specifically, the grafted dopamine neurons could produce clinical benefits that were significant and long lasting (reviewed in [6]). However, it also became clear that this approach produced inconsistent results with great variability between patients regarding the observed benefit. In some patients the cell implants produced significant side effects in the form of graft-induced dyskinesias (GIDs). The GIDs were most clearly illustrated in two NIH-sponsored double blind placebo control trials conducted towards the end of the 1990s [7, 8] and retrospective analyses of patients included in open label trials also concluded that some exhibited GIDs [9]. As a result, further experimental work was undertaken to better understand this variable response and why some patients developed such marked GIDs $[6,10]$. Following studies that shed light on mechanisms controlling GIDs, approaches to minimizing the risk of them occurring were developed and consequently a new European trial using fetal ventral mesencephalic tissue, called TRANSEURO (www.transeuro.org.uk), was initiated with the first surgeries performed in 2015. Given the inherent problems of using fetal tissue (including the ethical and logistical issues; reviewed in [11], the TRANSEURO trial was always considered to be a steppingstone to the upcoming generation of stem cell-derived 
dopamine cells. In other words, it was designed to lay the foundation for future stem cell-based transplantation trials in PD, through;

(i) better understanding which PD patients (precise clinical phenotype, age, time since onset of motor features) would maximally benefit from dopamine cell replacement;

(ii) standardizing how the ventral midbrain tissue would be prepared, delivered and supported in the grafted host;

(iii) better justified clinical trial end points that matched the time-course of a biological repair strategy, giving sufficient time to allow the grafted dopamine neurons to mature and integrate into the host brain.

Stem cell-based therapies are now approaching clinical trials in a number of centers. In order to ensure optimal progress toward the clinic a number of active groups in this field have set up a global initiative to collaborate on the translation of laboratory findings to trials: G-Force PD [12]. The aim of this consortium is to define criteria by which to gauge their own progress towards the clinic, while ensuring that all steps are conducted to the highest standard and that the trials are not initiated prematurely. A brief summary of these criteria have been summarised in a recent review [13].

How does the clinical transplantation trial in PD planned for 2016 by ISCO fare in light of the criteria defined by the G-Force-PD consortium? In the remainder of this article, we discuss the publicly available information from the planned ISCO trial. We have divided the discussion into five sections that each respond to one of the questions we posed in the first part of this article.

Question 1: What is being transplanted, and what is the proposed mechanism of action?

In the recently announced ISCO trial, the company will be transplanting neural stem cells differentiated from a pluripotent parthenogenetic cell line. The parthenogenetic cells have been derived from unfertilised oocytes through suppression of the second meiotic division, leading to a pluripotent diploid cell line containing exclusively maternal chromosomes [14]. These cells are therefore very different from other pluripotent cell sources such as embryonic stem cells (ESC) or induced pluripotent stem cells (iPSC), and their lack of paternal imprinting may be associated with unique challenges in their adoption clinically as this could affect their cell cycle and differentiation capacity $[15,16]$. For transplantation, ISCO proposes to use an expandable neural stem cell population that is derived from the parthenogenetic pluripotent cell source. The published data reveal that these cells are PAX6-positive [17], suggesting that they are of a dorsal neural fate. In contrast authentic midbrain dopaminergic neurons are derived from a PAX6-negative ventral midbrain neural precursor $[18,19]$. In line with this, the published data on the grafted PAX6-positive neural stem cells fails to show them giving rise to authentic midbrain dopaminergic neurons [20]. Thus as discussed below, it remains unclear as to how these cells could work in PD given that they do not form a replacement cell for the midbrain dopamine neurons that degenerate in this condition.

Question 2: What are the pre-clinical safety and efficacy data supporting the use of the proposed stem cell product?

The ability of stem cell-derived dopamine neurons to survive long term, innervate the host striatum and restore lost brain function in the 6-hydroxydopamine (6-OHDA) lesion rat PD model is essential for their development towards the clinic [5, 21]. For human ES cell-derived midbrain dopamine neurons, two independent groups have obtained results that match these criteria $[18,19,22]$. In both cases, the surviving transplants were observed months after being implanted with evidence of differentiation into midbrain dopamine cells, fiber outgrowth, dopamine release and restoration of motor deficits - in all cases without evidence of abnormal cellular proliferation or tumour growth. In a press release from April 2014, ISCO states that their parthenogenetic stem cells have been tested for efficacy in 18 MPTP-treated nonhuman primates, and that the transplanted animals showed "significant improvement in the main Parkinson's rating score" [23]. Unfortunately, these data have never been made public. In contrast, in a recent study, which is the only transplantation study the company has so far published, they instead state that they have tested the cells in 10 rats and only 2 monkeys, and they present no data on functional recovery in either species [20]. Thus, both the safety profile and proposed mechanism of action of the stem cells remain uncertain, especially given that the published study concludes that "Most of the engrafted hpNSCs were dispersed from the graft site and remained undifferentiated" [20]. Given the lack of dopaminergic neurons in the grafts, the authors propose that the cells might instead work through secretion of growth 
factors such as BDNF and GDNF [20]. This is not the first time such hypotheses have been put forward with cell based therapies for PD [24], namely that a cell therapy is proposed to work through trophic support to enhance endogenous function of dopaminergic neurons, and not by replacement of the degenerating dopamine neurons. However in the absence of plausible mechanisms and evidence in support of such hypotheses, this approach has previously been shown to result in clinical trials with poor outcomes [6]. The publicly available pre-clinical safety and efficacy data therefore clearly does not support the entry of these cells into a clinical trial at the present time. We can only speculate on whether additional preclinical safety and efficacy data has been submitted to regulatory bodies, and we strongly recommend a higher degree of transparency on the preclinical evidence.

Question 3: Can arguments concerning ethics, risk-mitigation or trial logistics outweigh concerns regarding the expected efficacy of the cell and constitute a primary justification for choosing one cell type over another in a clinical trial?

As fetal dopamine cell-based therapies were being developed in the 1980-1990s, many groups sought to use less ethically contentious cells, including cell grafts derived from the adrenal medulla; carotid body; fetal ventral mesencephalon derived from pigs; superior cervical ganglion and retinal pigmentary epithelial cells attached to microcarriers $\left(\right.$ Spheramine ${ }^{\circledR}$ ) [6]. These trials had the advantage that;

(a) they did not use aborted fetal tissue, which of course raises ethical issues;

(b) in the case of autografts they avoided the need for immunosuppression, and the risks to the transplanted patient linked to that;

(c) they ensured a readily available supply of tissue, and in case of Spheramine ${ }^{\circledR}$ this included a manufactured cell product.

Despite these advantages making the aforementioned cell sources superficially attractive alternatives, they do not preclude the absolute need to show that the transplanted cells survived, gave rise to reinnervation of the host brain and were behaviourally effective in pre-clinical models of PD. Indeed clinical success is dependent on whether the cell source can generate enough dopaminergic cells of the midbrain type that can survive transplantation and replace those lost in PD with a functional efficacy equivalent to that which has been seen with fetal dopaminergic neu- ronal grafts. For all of the five cell sources mentioned above, this was not shown - with only, at best, partial restoration of motor abnormalities in the unilateral 6-OHDA lesion rat PD model and limited numbers of surviving tyrosine hydroxylase-positive cells, typically with few or no axons innervating the host brain. In contrast, grafts of fetal human midbrain dopamine neurons have shown satisfactory pre-clinical data such as restoration of motor behaviours with evidence of graft survival and significant host brain innervation [3] and these cells have also shown therapeutic efficacy in patients [6].

This scenario is now being played out again with cell products derived from different types of stem cells. Some of these initiatives are driven by the wish to avoid the use of embryonic stem cells (ES cells), based on ethical concerns, claiming that the use of ES cells as the starting material is ethically problematic, or prohibitive, because their generation results in the destruction of a "viable" embryo [11]. These alternative stem cells include mesenchymal stem cells, which frequently are ascribed clinical properties with little support from the scientific literature, and induced pluripotent stem cells (iPSCs) derived from skin or blood cells from adult donors or from the patients themselves. In the case of the current trial sponsored by ISCO, parthenogenetic stem cells (i.e. cells derived from unfertilised oocytes) will be used. Because the oocytes are not fertilised or activated via sperm entry the ethical issues associated with ES cells are largely circumvented. However, arguing that the parthenogenetic cells are from an allegedly ethically more acceptable cell source does not obviate the need for meeting basic criteria for efficacy and safety testing. As long as no convincing preclinical efficacy data have been presented by ISCO, we do not consider the perceived ethical benefits associated with parthenogenetic stem cells justify their use in a clinical trial.

Question 4: What is being claimed regarding the potential therapeutic value of the stem cell-based therapy - better control of symptoms or a cure?

Many scientific and popular media articles claim that cell-based therapies for PD offer a real hope of a cure, although this would most likely require that the transplanted cells not only replace the lost dopamine innervation in the striatum, but are also capable of halting the disease progression resulting from alpha-synuclein pathology. Most cellbased therapies are designed to either replace the dopamine cells lost to the disease process, or rescue 
and maintain endogenous dopamine neurons that remain through the secretion of factors that are either neurotrophic or disease modifying in some way. This distinction on the mechanism by which the stem cell-derived product works can sometimes make it hard to understand what is being claimed, but in either case the treatment is simply trying to achieve a better dopaminergic therapy. The best outcome such a treatment can ever achieve is a restoration of striatal dopaminergic innervation to normal levels. This sort of clinical response has been demonstrated with fetal midbrain allografts with benefits that have been maintained over many years, and which has significantly improved the patients' quality of life and functional capacity, although still not offering a cure [25]. The clinical aim of a fully restored dopaminergic innervation is to replicate the best L-dopa response experienced by the patient, while avoiding the long term complications of L-dopa therapy related to its non-physiological stimulation of dopamine receptors in the striatum and at extra-striatal sites. Even with complete restoration of dopamine neurotransmission, it remains to be determined if dopamine neuron grafts can be effective in very advanced $P D$, which is characterised by alphasynuclein aggregates in widespread brain regions. Therefore, claims of cures should be avoided when these cell replacement therapies are being discussed, and the more measured claims being made in the recent press release from ISCO are more in line with what is being hoped for with such treatments.

Question 5: What is the regulatory oversight of the trial and is it guided by input from experts in the field?

The translation of a therapy from the lab to the clinic is not straightforward, especially when the new treatment is an experimental biological product. This progress toward a first in human clinical trial obviously requires sufficient high quality pre-clinical evidence to support its use (see above), while the regulatory authorities will primarily want to see evidence that it is safe. This latter issue has meant that many new treatments of this type have come to clinic ahead of their pre-clinical efficacy data, and the clinicians who are asked to lead the clinical trials may not feel qualified to comment on the validity of the pre-clinical data. Therefore, it is imperative to ensure that the clinicians undertaking and overseeing such trials have the necessary expertise to assess the claims attached to the treatment by critically appraising the pre-clinical safety and efficacy data, and if they do not have this expertise, seek the advice of those who do. In this regard, and for the sake of transparency, the pre-clinical data used to justify the initiation of a clinical trial should be made available to both the scientific and the patient communities. In terms of the trial itself, there are currently no clear guidelines as to what this should look like, especially in the case of first-in-human studies. However, the topic warrants a few comments. Firstly, the trial should be in receipt of the necessary independent ethical and regulatory approval of the country where it is being done, and have as part of its structure an independent data monitoring committee of relevant experts. Secondly, the trial should be fully funded without the patients having to pay or raise money for the trial to be a part of it (http://www.isscr.org/home/publications/ClinTrans Guide). Thirdly, the trial should have long term follow up with a number of rigorous measures being collected systematically, including not only data on safety but also on functional efficacy ideally using objective measures of dopaminergic pathway integrity in the grafted brain, e.g. using F-dopa positron emission tomography (PET) scans. In the study that will be launched in 2016 by ISCO, the follow up will only be for one year which almost certainly will not be long enough to detect clinical improvement if there is any [7, 26]. Nor will a one year follow-up period be long enough to detect slow neural overgrowth [27] or to assess the unknown risks associated with any cell derived from a pluripotent stem cell source, and in particular from a parthenogenetic stem cell source [27]. Finally, the data of any such trial should be published or made publicly available by other means regardless of the outcome, and any conflicts of interest explicitly declared by all the authors of that paper.

\section{CONCLUSIONS}

As our ability to make authentic midbrain dopaminergic neurons from stem cell sources improves, so does the reality of a first in human clinical trial in patients with PD. This is an exciting prospect but should only be undertaken when all the necessary pre-clinical data and regulatory approvals have been obtained and verified and the criteria for moving those cells to trials fully resolved and met - something that is currently a major focus of the GForce-PD consortium (www.gforce-pd.com/). Only too often are exaggerated claims made, based on limited pre-clinical data and a desire to pass the 
financial and regulatory hurdles needed to get to clinic, sometimes driven by personal ambitions along with financial and commercial interests. Acting prematurely has the potential not only to tarnish many years of scientific work, but can threaten to derail and damage this exciting field of regenerative medicine. Hopefully, in 2016, we are ready to take a more careful approach as we strive to repair the PD brain with stem cell-based therapies, avoiding many of the mistakes that have dogged this field over the last 3 decades [28].

\section{ACKNOWLEDGMENTS}

Some of the work discussed in this commentary was supported by grants from the EU FP 7 programme including TRANSEURO and NeuroStemCellRepair, and the Swedish Research Council. RAB is also supported by an NIHR grant of a Biomedical Research Centre to Addenbrooke's Hospital and the University of Cambridge.

\section{REFERENCES}

[1] (2015) Press Release International Stem Cell Corporation Receives Authorization to Initiate Phase I/IIa Clinical Trial of ISC-hpNSC for the Treatment of Parkinson's Disease: http://www.internationalstemcell.com/profiles/investor/ ResLibraryView.asp?ResLibraryID $=80072 \&$ GoTopage $=1$ $\&$ Category $=958 \&$ BzID $=1468 \& G=583$

[2] (2015) Press release, International Stem Cell Corporation. http://www.internationalstemcell.com/profiles/investor/ NewsPrint.asp $? \mathrm{~b}=1468 \& I D=80129 \& \mathrm{~m}=\mathrm{rl} \& \mathrm{pop}=1 \& \mathrm{Nav}=$ $0 \& \mathrm{~g}=583 \& \mathrm{t}=1983$.

[3] Brundin P, Strecker RE, Clarke DJ, Widner H, Nilsson OG, Astedt B, Lindvall O, \& Bjorklund A (1988) Can human fetal dopamine neuron grafts provide a therapy for Parkinson's disease? Prog Brain Res, 78, 441-448.

[4] Brundin P, Barker RA, \& Parmar M (2010) Neural grafting in Parkinson's disease Problems and possibilities. Prog Brain Res, 184, 265-294.

[5] Thompson L, \& Bjorklund A (2012) Survival, differentiation, and connectivity of ventral mesencephalic dopamine neurons following transplantation. Prog Brain Res, 200, 61-95.

[6] Barker RA, Drouin-Ouellet J, \& Parmar M (2015) Cellbased therapies for Parkinson disease-past insights and future potential. Nat Rev Neurol, 11, 492-503.

[7] Freed CR, Greene PE, Breeze RE, Tsai WY, DuMouchel W, Kao R, Dillon S, Winfield H, Culver S, Trojanowski JQ, Eidelberg D, \& Fahn S (2001) Transplantation of embryonic dopamine neurons for severe Parkinson's disease. $N$ Engl J Med, 344, 710-719.

[8] Olanow CW, Goetz CG, Kordower JH, Stoessl AJ, Sossi V, Brin MF, Shannon KM, Nauert GM, Perl DP, Godbold J, \& Freeman TB (2003) A double-blind controlled trial of bilateral fetal nigral transplantation in Parkinson's disease. Ann Neurol, 54, 403-414.
[9] Hagell P, Piccini P, Bjorklund A, Brundin P, Rehncrona S, Widner H, Crabb L, Pavese N, Oertel WH, Quinn N, Brooks DJ, \& Lindvall O (2002) Dyskinesias following neural transplantation in Parkinson's disease. Nat Neurosci, 5, 627-628.

[10] Barker RA, Barrett J, Mason SL, \& Bjorklund A (2013) Fetal dopaminergic transplantation trials and the future of neural grafting in Parkinson's disease. Lancet Neurol, 12, 84-91.

[11] Barker RA, \& de Beaufort I (2013) Scientific and ethical issues related to stem cell research and interventions in neurodegenerative disorders of the brain. Prog Neurobiol, 110, 63-73.

[12] Abbott A (2014) Fetal-cell revival for Parkinson's. Nature, 510, 195-196.

[13] Barker RA, Studer L, Cattaneo E, Takahashi J, G-Force PD consortium (2015) G-Force PD: A global initiative in coordinating stem cell-based dopamine treatments for Parkinson's disease. NPJ Parkinson's Disease, published online 24 September 2015

[14] Revazova ES, Turovets NA, Kochetkova OD, Kindarova LB, Kuzmichev LN, Janus JD, \& Pryzhkova MV (2007) Patient-specific stem cell lines derived from human parthenogenetic blastocysts. Cloning Stem Cells, 9, 432449.

[15] Fundele RH, Norris ML, Barton SC, Fehlau M, Howlett SK, Mills WE, \& Surani MA (1990) Temporal and spatial selection against parthenogenetic cells during development of fetal chimeras. Development, 108, 203-211.

[16] Hernandez L, Kozlov S, Piras G, \& Stewart CL (2003) Paternal and maternal genomes confer opposite effects on proliferation, cell-cycle length, senescence, and tumor formation. Proc Natl Acad Sci U S A, 100, 13344-13349.

[17] Gonzalez R, Garitaonandia I, Abramihina T, Wambua GK, Ostrowska A, Brock M, Noskov A, Boscolo FS, Craw JS, Laurent LC, Snyder EY, \& Semechkin RA (2013) Deriving dopaminergic neurons for clinical use. A practical approach. Sci Rep, 3, 1463.

[18] Kirkeby A, Grealish S, Wolf DA, Nelander J, Wood J, Lundblad M, Lindvall O, \& Parmar M (2012) Generation of regionally specified neural progenitors and functional neurons from human embryonic stem cells under defined conditions. Cell Rep, 1, 703-714.

[19] Kriks S, Shim JW, Piao J, Ganat YM, Wakeman DR, Xie Z, Carrillo-Reid L, Auyeung G, Antonacci C, Buch A, Yang L, Beal MF, Surmeier DJ, Kordower JH, Tabar V, \& Studer L (2011) Dopamine neurons derived from human ES cells efficiently engraft in animal models of Parkinson's disease. Nature, 480, 547-551.

[20] Gonzalez R, Garitaonandia I, Crain A, Poustovoitov M, Abramihina T, Noskov A, Jiang C, Morey R, Laurent LC, Elsworth JD, Snyder EY, Redmond DE, Jr., \& Semechkin R (2015) Proof of concept studies exploring the safety and functional activity of human parthenogenetic-derived neural stem cells for the treatment of Parkinson's disease. Cell Transplant, 24, 681-690.

[21] Barker RA (2014) Developing stem cell therapies for Parkinson's disease: Waiting until the time is right. Cell Stem Cell, 15, 539-542.

[22] Grealish S, Diguet E, Kirkeby A, Mattsson B, Heuer A, Bramoulle Y, Van Camp N, Perrier AL, Hantraye P, Bjorklund A, \& Parmar M (2014) Human ESC-derived dopamine neurons show similar preclinical efficacy and potency to fetal neurons when grafted in a rat model of Parkinson's disease. Cell Stem Cell, 15, 653-665. 
[23] (2014) International Stem Cell Corporation. http://www. internationalstemcell.com/profiles/investor/ResLibrary View.asp?ResLibraryID $=69735 \&$ GoTopage $=5 \&$ Category $=$ 958\&BzID $=1468 \& \mathrm{G}=583$.

[24] Gross RE, Watts RL, Hauser RA, Bakay RA, Reichmann H, von Kummer R, Ondo WG, Reissig E, Eisner W, SteinerSchulze H, Siedentop H, Fichte K, Hong W, Cornfeldt M, Beebe K, Sandbrink R, \& Spheramine Investigational G (2011) Intrastriatal transplantation of microcarrier-bound human retinal pigment epithelial cells versus sham surgery in patients with advanced Parkinson's disease: A doubleblind, randomised, controlled trial. Lancet Neurol, 10, 509-519.

[25] Kefalopoulou Z, Politis M, Piccini P, Mencacci N, Bhatia K, Jahanshahi $\mathrm{M}$, Widner $\mathrm{H}$, Rehncrona $\mathrm{S}$, Brundin $\mathrm{P}$, Bjorklund A, Lindvall O, Limousin P, Quinn N, \& Foltynie T (2014) Long-term clinical outcome of fetal cell transplantation for Parkinson disease: Two case reports. JAMA Neurol, 71, 83-87.

[26] Ma Y, Tang C, Chaly T, Greene P, Breeze R, Fahn S, Freed C, Dhawan V, \& Eidelberg D (2010) Dopamine cell implantation in Parkinson's disease: Long-term clinical and (18)F-FDOPA PET outcomes. J Nucl Med, 51, 7-15.

[27] Aubry L, Bugi A, Lefort N, Rousseau F, Peschanski M, \& Perrier AL (2008) Striatal progenitors derived from human ES cells mature into DARPP32 neurons in vitro and in quinolinic acid-lesioned rats. Proc Natl Acad Sci U S A, 105, 16707-16712.

[28] Bianco P, Barker R, Brustle O, Cattaneo E, Clevers H, Daley GQ, De Luca M, Goldstein L, Lindvall O, Mummery C, Robey PG, Sattler de Sousa EBC, \& Smith A (2013) Regulation of stem cell therapies under attack in Europe: For whom the bell tolls. EMBO J, 32, 1489-1495. 